\title{
Анализ экспрессии гена $Q$, контролирующего ряд важных признаков пшениц, включенных в процесс доместикации и селекции
}

\author{
К.А. Головнина ${ }^{1}$, А.Г. Блинов ${ }^{2}, 3$, В.И. Майоров ${ }^{4}$, Н. Ватанабе ${ }^{5}$, Н.П. Гончаров ${ }^{2} 凶$
}

Аннотация: Анализ экспрессии гена $Q$, контролирующего основные признаки, по которым человек вел отбор у пшениц (род Triticum L.) в процессе доместикации и селекции, показал, что формирование морфологии колоса возделываемых видов пшениц действительно зависит от уровня экспрессии этого гена. На основании результатов работы установлено, что кроме нарушения в позиции 329 Q белка на его функцию и морфологию колоса пшениц также оказывают влияние другие факторы и гены. Ключевые слова: пшеница; доместикация; ломкоколосость.

Благодарности: Считаем своим приятным долгом поблагодарить проф. Н. Тsujimoto (Университет г. Тоттори, Япония) за предоставление изогенных линий сорта Chinese Spring. Работа по изучению экспрессии генов поддержана бюджетным проектом ИЦиГ СО РАН № 0324-2019-0039-С-01, в части изучения селекционного материала (линии 16Н1598 и 16Н1534) работа финансировалась по программе Министерства сельского хозяйства PK (BR10765056).

Для цитирования: Головнина К.А., Блинов А.Г., Майоров В.И., Ватанабе Н., Гончаров Н.П. Анализ экспрессии гена Q, контролирующего ряд важных признаков пшениц, включенных в процесс доместикации и селекции. Письма в Вавиловский журнал генетики и селекции. 2021;7(4):172-175. DOI 10.18699/LettersVJ2021-7-22

\section{Expression analysis of $Q$ gene, controlling of the important domestication and breeding wheat traits}

\author{
K.A. Golovnina ${ }^{1}$, A.G. Blinov ${ }^{2}, 3$, V.I. Mayorov ${ }^{4}$, N. Watanabe ${ }^{5}$, N.P. Goncharov ${ }^{2} \bowtie$
}

Abstract: Analysis of the expression of the $Q$ gene (spelt factor), controlling the main agronomic traits by which a human had selected wheat (Triticum L.) during domestication and breeding, showed that the formation of the ear morphology of cultivated wheat species really depends on the level of expression of this gene. Based on the results of these investigation, it was found that in addition to a violation in the 329 Q position of the protein, its function and morphology of the wheat ear are also influenced by other factors and genes.

Key words: wheat; domestication; fragility.

For citation: Golovnina K.A., Blinov A.G., Mayorov V.I., Watanabe N., Goncharov N.P. Expression analysis of $Q$ gene, controlling of the important domestication and breeding wheat traits. Pisma v Vavilovskii Zhurnal Genetiki i Selektsii = Letters to Vavilov Journal of Genetics and Breeding. 2021;7(4):172-175. DOI 10.18699/LettersVJ2021-7-22 (in Russian)

${ }^{1}$ Миллипоре Сигма, Роквилл, Мэриленд, США

US Molecular Operations, Process Solution Services (BioReliance ${ }^{\oplus}$ ), MilliporeSigma. Rockville, MD, USA

2 Федеральный исследовательский центр Институт цитологии и генетики Сибирского отделения Российской академии наук, Новосибирск, Россия

Institute of Cytology and Genetics of the Siberian Branch of the Russian Academy of Sciences, Novosibirsk, Russia

3 Институт молекулярной и клеточной биологии Сибирского отделения Российской академии наук, Новосибирск, Россия

Institute of Molecular and Cellular Biology of the Siberian Branch of the Russian Academy of Sciences, Novosibirsk, Russia

4 Мерсер университет, Мэйкон, США

Mercer University School of Medicine, Macon GA, USA

5 Колледж сельского хозяйства, Университет г. Ибараки, Ибараки, Япония

College of Agriculture, Ibaraki University, Ibaraki, Japan

هonch@bionet.nsc.ru

() Головнина К.А., Блинов А.Г., Майоров В.И., Ватанабе Н., Гончаров Н.П., 2021 
Поиск и всестороннее изучение генов, «включенных» в неолитическую революцию, становится все более популярной темой исследований (Doebley et al., 2006; Lev-Yadun et al., 2006; Abbo, Gopher, 2017; и др.). Ген $Q$ является одним из генов пшениц (род Triticum L.), которые контролируют основные признаки, включенные в доместикацию, а именно «пленчатость-голозерность» и «ломкоколосость» (Tanno, Willcox, 2006; Гончаров и др., 2007а). Контроль этих признаков обусловливает важную роль гена $Q$ в широком распространении голозерных видов пшениц - твердой пшеницы (Triticum durum Desf.) и мягкой пшеницы (T.aestivum L.) в культуре по сравнению с редко возделываемыми в настоящее время пленчатыми видами, такими как спельта (T. spelta L.), полба (T. dicoccum (Shrank) Schübl. (syn. T. turgidum ssp. dicoccum (Shrank ex Schübl.) Thell.)), T. tibetanum и T. yunnanense (Stallknecht et al., 1996; Ионов и др., 2013; Кобылянский и др., 2013; van Slageren, Payne, 2013; Фу Хао, Гончаров, 2019). Однако в последнее время их все чаще используют для получения продуктов функционального питания (Arzani, Ashraf, 2017). Более того, селекционеры создают голозерные аналоги пленчатых видов (Патент..., 2007), запутывая (Смекалова, Кобылянский, 2019) и так непростую таксономию пленчатых пшениц (van Slageren, Payne, 2013).

Недавно была установлена последовательность гена $Q$ и показана его гомология гену транскрипционного фактора APETALA2 (AP2) Arabidopsis thaliana (L.) Heynh (Simons et al., 2006). Ген локализован в длинном плече хромосом 5-й гомеологической группы пшениц. Основная функциональная роль осталась только у одной копии гена $Q$ на хромосоме $5 \mathrm{~A}$ (Simons et al., 2006; Zhang et al., 2011). Функциональное значение гомологичных локусов на хромосомах 5B и 5D не выяснено. В результате мутационных событий, произошедших B генах геномов B и D, оба транскрипта с B генома и один с D генома оказались нарушенными (Zhang et al., 2011). Однако гомологи гена $Q$ у доноров B и D геномов полиплоидных пшениц - диких диплоидных видов эгилопсов - Aegilops speltoides Tausch и Ae.tauschii Coss. (син. Ae. squarrosa L.) продуцируют белок без каких-либо нарушений или повреждений (Ning et al., 2009; Zhang et al., 2011).

Сравнительный анализ последовательностей этого гена у представителей рода Triticum с генотипами qq (голозерность) и $Q Q$ (пленчатость) 1 позволил выявить точечную мутацию в белок-кодирующей области (Val329lle), которая, вероятно, и повлияла на появление признака «голозерность» и формирование ломкого колоса (Simons et al., 2006).

Для выяснения функции гена $Q$ у представителей рода, имеющих различную морфологию колоса и наличие/отсутствие мутации Val329lle, в данной работе был проведен анализ экспрессии гена $Q$ у 10 образцов различных видов пшениц трех уровней плоидности (см. таблицу). Эксперименты проводили в режиме реального времени (real-time PCR) по технологии SYBR Green на аппарате Applied Biosystems 7300 Real-Time PCR System. Необходимые пары праймеров были выбраны в программах Primer Premier и Primer 3. Затем проведен градиентный ПЦР для определения оптимальной

\footnotetext{
1 Данные о доминантности-рецессивности приведены в соответствии с данными генетического анализа (Гончаров, 2012).
}

температуры отжига праймеров. Для сравнения графиков, полученных при проведении ПЦР в режиме реального времени, был использован пороговый метод ( $C_{t}$ threshold cycle). Выделение PHK проводили по протоколу SV Total RNA Isolation System (Promega).

Исследование экспрессии на разных стадиях развития растений показало наличие взаимосвязи количества синтезируемого продукта гена $Q$ с морфологией колоса у двух пар родственных видов: 1) пленчатая T. dicoccoides (Körn. ex Aschers. et Graebn.) Schweinf. и голозерная T. aestivum L. и 2) пленчатая T. monococcum L. и голозерная T. sinskajae A. Filat. et Kurk. Экспрессия гена $Q$ у голозерных пшениц выше, чем у пленчатых (см. рисунок).

У проростков в фазе третьих листьев ген $Q$ экспрессировался активнее у образцов диплоидных видов эгилопсов (Ae. speltoides, Ae. squarrosa), его высокая активность сохранялась также и у взрослых растений этих видов (см. рисунок). На основе анализа последовательностей гена $Q$ и результатах гибридологического анализа было сделано заключение, что форма колоса у эгилопсов и диких диплоидных пшениц не зависит от уровня экспрессии гена $Q$. Bсе они имеют пленчатый колос и высокую активность гена $Q$ по сравнению с тетраплоидной пшеницей T. dicoccoides. Взаимосвязь морфологии колоса с количеством продукта гена $Q$ прослеживается на примере образцов культурной однозернянки T. monococcum и ее голозерного мутанта T. sinskajae (T. sinskajae - единственный голозерный представитель диплоидных видов (Гончаров и др., 20076)). Показано, что основные видоспецифические изменения у этого вида произошли в длинном плече хромосомы 5А, где локализован и ген $Q$ (Гончаров и др., 20076). Экспрессия этого гена у данного вида заметно выше, что подтверждает предыдущие данные об увеличении экспрессии гена у голозерных, более компактных форм (Simons et al., 2006). Хотя в настоящее время установлено, что компактность колоса не зависит, как считали ранее, от дозы гена $Q$, а связана с расположенным на близком расстоянии с ним геном Sp1 (Kosuge et al., 2012). Более того, оба вида содержат ІІе в позиции 329 гена Q. Это означает, что мутация в кодирующей области в данном случае не имеет функционального значения.

Изогенные линии $16 \mathrm{H} 1534$ (i: CS*7/T. spelta) и $16 \mathrm{H} 1598$ (i: CS*7/T. dicoccoides) мягкой пшеницы сорта Chinese Spring (CS), полученные H. Tsujimoto (2001), с генами $Q$ и $Q^{b}$ от T. dicoccoides и T. spelta содержат $Q$ белок c Val в позиции 329 и спельтоидный, пленчатый фенотип колоса, как и родительские пленчатые формы, от которых получен аллель гена $Q$. Однако на первых этапах развития растения экспрессия гена $Q$ у этих линий заметно снижена по сравнению с родительскими формами. При переходе к колошению экспрессия возрастает у изогенной линии CS*7/T. spelta и образца KU 3377 T. spelta из Ирана, тогда как у изогенной линии CS*7/T.dicoccoides и образца PI467005 пленчатого вида T.dicoccoides она, напротив, падает (см. рисунок). Полученные данные говорят о разной регуляции гена $Q$ и его роли в морфогенезе колоса. Гибридологический анализ показывает, что гены, ответственные за проявление признаков «спельтоидность» и «пленчатость» у изогенных линий с генами $Q$ от T. dicoccoides и T. spelta не аллельны (Sood et 
Морфология колоса и вариабельная позиция 2094 в последовательности гена $Q$ у видов пшениц и эгилопсов

\begin{tabular}{|c|c|c|c|c|}
\hline \multirow{3}{*}{ Вид, образец } & \multicolumn{3}{|c|}{ Признаки, определяющие морфологию колоса } & \multirow{2}{*}{$\begin{array}{l}\text { Полиморфная } \\
\text { аминокислота } \\
329 \mathrm{Val} / \mathrm{lle} \\
\text { Экзон } 8\end{array}$} \\
\hline & \multirow{2}{*}{ Пленчатость } & \multirow{2}{*}{ Ломкоколосость } & \multirow{2}{*}{ Спельтоидность } & \\
\hline & & & & 2094 п.н. \\
\hline Ae46566 Ae. speltoides & + & - & + & C \\
\hline к-865 Ae. tauschii & + & + & $+^{1}$ & $\mathrm{C}$ \\
\hline к-48993 T. sinskajae [?] ${ }^{2}$ & - & - & - & G \\
\hline K-18105 T. monococcum [?] ${ }^{2}$ & + & - & + & G \\
\hline IG44829 T. urartu [?] ${ }^{2}$ & + & + & + & G \\
\hline PI467005 T. dicoccoides $\left[Q^{\mathrm{b}}\right]^{2}$ & + & + & + & G \\
\hline 16H1598 i: $C S^{*} 7 /$ T. dicoccoides $\left[Q^{\mathrm{b}}\right]^{2}$ & + & + & + & G \\
\hline T. aestivum сорт Chinese Spring $[q]^{2}$ & - & - & - & A \\
\hline KU3377 T. spelta $[Q]^{2}$ & + & + & + & G \\
\hline $16 \mathrm{H} 1534$ i: $C S^{*} 7 /$ T. spelta $[Q]^{2}$ & + & + & + & G \\
\hline
\end{tabular}

${ }^{1}$ Спельтоидность обусловлена геном Tg (Sood et al., 2009; Гончаров, 2012).

${ }^{2}$ B квадратных скобках обозначение аллелей гена $Q$ на основании результатов генетического анализа согласно (Sormacheva et al., 2015).

[?] - аллельное состояние гена $Q$ не определено (см.: Гончаров и др., 20076; Vavilova et al., 2020).

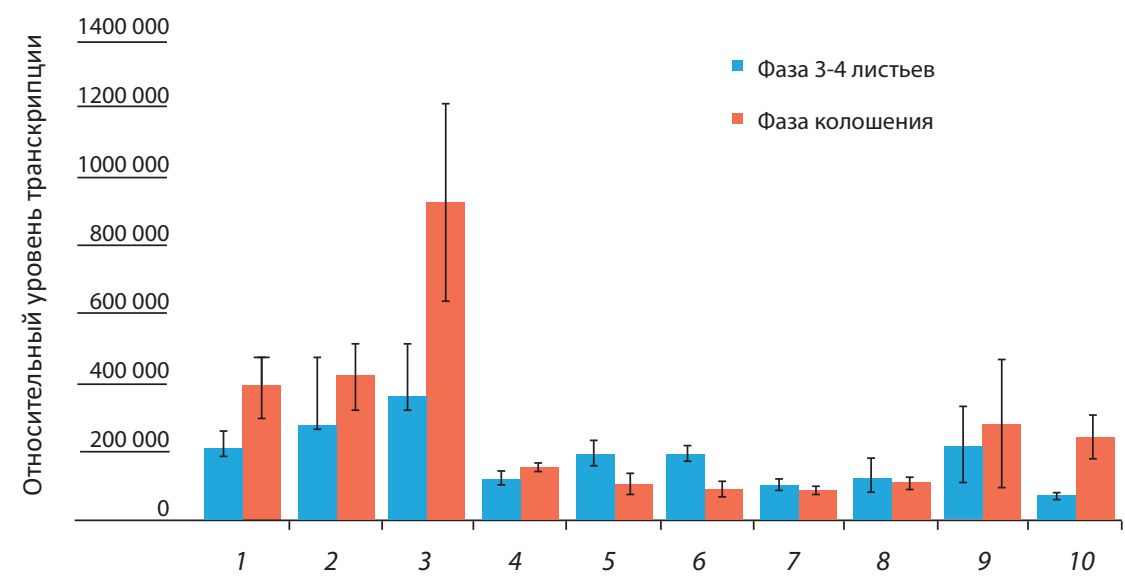

Уровень экспресии гена $Q$ у пшениц и эгилопсов в фазе третьих листьев и фазе колошения.

1 - Ae. speltoides, 2 - Ae. tauschii, 3 - T. sinskajae, 4 - T. monococcum, 5 - T. urartu, 6 - T. dicoccoides, 7 - i: CS*7/T. dicoccoides, $8-$ T. aestivum (CS), $9-$ T. spelta, $10-i: C S^{*} 7 /$ T. spelta

al., 2009), однако в последовательности белка Q у них присутствует Val в позиции 329. Показано, что именно замена аминокислоты в этой позиции приводит к появлению неспельтоидного колоса T. aestivum и увеличению экспрессии гена $Q$ (Simons et al., 2006).

Ранее экспрессия гена $Q$ была исследована только у замещенной линии $T$. aestivum/5A T. dicoccoides и мутантных форм мягкой пшеницы (Simons et al., 2006; Zhang et al., 2011). В результате проведенного нами анализа обнаружено, что действительно его экспрессия у мягкой пшеницы с голозерным, неспельтоидным типом колоса увеличена по сравнению с изогенной линией $\mathrm{CS}^{*} 7 / T$. dicoccoides, характеризуемой пленчатостью и спельтоидным колосом (см. рисунок). Однако у мягкой пшеницы экспрессия гена $Q$ не превышает уровень экспрессии этого же гена у пленчатого вида T. spelta. Поэтому можно сделать вывод о том, что контроль гена $Q$ у двух спельтоидных видов: тетраплоидного $T$. dicoccoides и гексаплоидного T. spelta - осуществляется по-разному. Происхождение голозерной мягкой пшеницы от пленчатой $T$. dicoccoides со спельтоидным колосом, так же как и голозерной T. sinskajae от пленчатой T. monococcum, вполне вероятно связано с наблюдаемым нарушением экспрессии гена $Q$. В результате синтез большего количества продукта, кодируемого геном $Q$, привел к изменениям морфологии колоса. В то время как эволюция его функции у T. spelta шла независимо.

На основе полученных результатов мы не можем подтвердить вывод о том, что именно описанная мутация в по- 
зиции 329 у мягкой пшеницы приводит к смене фенотипа и связана с регуляцией экспрессии и количеством продукта (Simons et al., 2006). Более подробные исследования локуса $Q$ в геномах A, B и D подтверждают, что на экспрессию и функцию гена $Q$ влияет не только мутация Val329lle в A геноме, но также и комбинация мутаций и аллелей в локусах В и D геномов (Zhang et al., 2011).

Следует отметить, что замена в позиции 329 у полиплоидных пшениц приводит к смене фенотипа, в то время как у диплоидных видов пшениц - не приводит.

\section{Список литературы / References}

Гончаров Н.П. Сравнительная генетика пшениц и их сородичей. Изд. 2-е, испр. и доп. Новосибирск: Акад. изд-во «Гео», 2012.

[Goncharov N.P. Comparative Genetics of Wheats and their Related Species. $2^{\text {nd }}$ edn. Academic Publ. House "Geo", 2012. (in Russian)]

Гончаров Н.П., Глушков С.А., Шумный В.К. Доместикация злаков Старого Света: поиск новых подходов для решения старой проблемы. Журнал общей биологии. 2007а;68(2):126-148.

[Goncharov N.P., Glushkov S.A., Shumny V.K. Domestication of cereal crops in the old world: in search of a new approach to solving old problem. Zhurnal Obshchey Biologii = Biology Bulletin Reviews. 2007a;68(2):126-148. (in Russian)]

Гончаров Н.П., Кондратенко Е.Я., Банникова С.В., Коновалов А.А., Головнина К.А. Сравнительно-генетический анализ голозерной диплоидной пшеницы Triticum sinskajae и ее исходной формы T. mопососсит. Генетика. 20076;43(11):1491-1500. DOI 10.1134/ S1022795407110075

[Goncharov N.P., Kondratenko E.J., Bannikova S.V., Konovalov A.A. Golovnina K.A. Comparative genetic analysis of diploid naked wheat Triticum sinskajae and the progenitor T.monococcum accession. Russ.J. Genet. 2007b;43(11):1248-1256. DOI 10.1134/S1022795407110075.]

Ионов Э.Ф., Мережко А.Ф., Тимербекова С.К., Ионова Н.Э. Характеристика новой крупяной культуры-голозерной полбы, сорт Греммэ. Труды по прикладной ботанике, генетике и селекции. 2013;171:287-288.

[lonov E.F., Merezhko A.F., Temirbekova S.K., lonova N.E. Characteristics of a new cereal crop-naked spelt, Gremme variety. Trudy po Prikladnoy Botanike, Genetike i Selektsii = Proceedings on Applied Botany, Genetics, and Breeding. 2013;171:287-288. (in Russian)]

Кобылянский В.Д., Сурин Н.А., Попова Н.М. Агробиологическая оценка образцов голозерной полбы в условиях Красноярской лесостепи. Фундаментальные исследования. 2013;3(10):601-605. [Kobylyansky V.D., Surin N.A., Popova N.M. The agrobiologic evaluation of samples spelt in conditions Krasnoyarsk forest steppe. Fundamentalnye Issledovaniya = Fundamental Research. 2013;3(10):601 605. (in Russian)]

Патент на селекционное достижение № 4782 Российская Федерация. Пшеница полба (Triticum turgidum L. subsp. dicoccum (Schrank ex Schübl.) Thell.). Сорт Руно: № 47176: заявл. 15.01.2007 / Л.И. Шуровенкова, Н.А. Анфилова, А.Ф. Мережко, Л.А. Беспалова, И.Н. Кудряшов, А.В. Васильев, А.Н. Боровик, О.П. Митрофанова; заявитель Национальный центр зерна им. П.П. Лукьяненко Федеральный исследовательский центр Всероссийский институт генетических ресурсов растений им. Н.И. Вавилова. [Patent for breeding achievement No. 4782 Russian Federation. Emmer wheat (Triticum turgidum L. subsp. dicoccum (Schrank ex Schübl.) Thell.). Cv. Runo: No. 47176: application No. 15.01.2007 / L.I. Shurovenkova, N.A. Anfilova, A.F. Merezhko, L.A. Bespalova I.N. Kudryashov, A.V. Vasiliev, A.N. Borovik, O.P. Mitrofanova; applicant National Grain Center named after P.P. Lukyanenko, Federal Research Center N.I. Vavilov All-Russian Institute of Plant Genetic Resources. (in Russian)]

Смекалова Т.Н., Кобылянский В.Д. Новый подвид пшеницы Triticum dicoccon (Schrank) Schuebl. subsp. nudicoccon Kobyl. et
Smekal. Труды по прикладной ботанике, генетике и селекции. 2019;180(4):148-151. DOI 10.30901/2227-8834-2019-4-148-151.

[Smekalova T.N., Kobylyansky V.D. A new subspecies of wheat: Triticum dicoccon (Schrank) Schuebl. subsp. nudicoccon Kobyl. et Smekal. Trudy po Prikladnoy Botanike, Genetike $i$ Selektsii = Proceedings on Applied Botany, Genetics, and Breeding. 2019;180(4):148-151. DOI 10.30901/2227-8834-2019-4-148-151. (in Russian)]

Фу Хао, Гончаров Н.П. Эндемичные пшеницы Китая как ресурсы селекции. Генетичні ресурси рослин. 2019;25:11-25. DOI 10.36814/ pgr.2019.25.01

[Fu Hao, Goncharov N.P. Endemic wheat of China as breeding resources. Plant Genetic Resources. 2019;25:11-25. DOI 10.36814/ pgr.2019.25.01. (in Russian)]

Abbo S., Gopher A. Near Eastern plant domestication: a history of thought. Trends in Plant Science. 2017;22(6):491-511. DOI 10.1016/j. tplants.2017.03.010.

Arzani A., Ashraf M. Cultivated ancient wheats (Triticum spp.): A potential source of health-beneficial food products. Comprehensive Reviews Food Science Food Safety. 2017;16(3):477-488. DOI 10.1111/15414337.12262.

Doebley J. Unfallen grains: how ancient farmers turned weeds into crops. Science. 2006;312(5778):1318-1319. DOI 10.1016/j.cell.2006.12.006.

Kosuge K., Watanabe N., Melnik V.M., Laikova L.I., Goncharov N.P. New sources of compact spike morphology determined by the genes on chromosome 5A in hexaploid wheat. Genet. Resour. Crop Evol. 2012;59(6):1115-1124. DOI 10.1007/s10722-011-9747-9.

Lev-Yadun S., Gopher A., Abbo S., Hartmann A., Kislev M.E., Weiss E. How and when was wild wheat domesticated? Science. 2006:313(5785):296.

Ning S.-Z., Chen Q.-J., Yuan Z.-W., Zhang L.-Q., Yan Z.-H., Zheng Y.-L., Liu D.-C. Characterization of WAP2 gene in Aegilops tauschii and comparison with homoeologous loci in wheat. J. Syst. Evol. 2009;47:543551. DOI 10.1111/j.1759-6831.2009.00048.x.

Simons K.J., Fellers J.P., Trick H.N., Zhang Z., Tai Y.S., Gill B.S., Faris J.D. Molecular characterization of the major wheat domestication gene $Q$. Genetics. 2006;172:547-555. DOI 10.1534/genetics.105.044727.

Sood S., Kuraparthy V., Bai G., Gill B.S. The major threshability genes soft glume (sog) and tenacious glume ( $\mathrm{Tg})$, of diploid and polyploid wheat, trace their origin to independent mutations at non-orthologous loci. Theor. Appl. Genet. 2009;119:341-351. DOI 10.1007/s00122009-1043-0.

Sormacheva I., Golovnina K., Kosuge K., Watanabe N., Blinov A., Goncharov N.P. $Q$ gene variability in wheat species with the different spike morphology. Genet. Resour. Crop Evol. 2015;62(6):837-852. DOI 10.1007/s10722-014-0195-1.

Stallknecht G.F., Gilbertson K.M., Ranney J.E. Alternative wheat cereals as food grains: einkorn, emmer, spelt, kamut, and triticale. In: J. Janick (Ed.) Progress in new crops. ASHS Press, Alexandria, 1996;156-170.

Tanno K., Willcox G. How fast was wild wheat domesticated? Science. 2006;311:1886. DOI 10.1126/science.1124635.

Tsujimoto $\mathrm{H}$. Production of near-isogenic lines and marked monosomic lines in common wheat (Triticum aestivum) cv. Chinese Spring. J. Hered. 2001;93(3):254-259. DOI 10.1093/jhered/92.3.254.

van Slageren M., Payne T. Concepts and nomenclature ofthe farro wheats, with special reference to emmer, Triticum turgidum subsp. dicoccum (Poaceae). Kew Bull. 2013;68:477-494.

Vavilova V., Konopatskaia I., Blinov A., Kondratenko E.Ya., Kruchinina Y.V., Goncharov N.P. Genetic variability of spelt factor gene in Triticum and Aegilops species. BMC Plant Biol. 2020;20(Suppl. 1):310. DOI 10.1186/ s12870-020-02536-8.

Zhang Z., Belcram H., Gornicki P., Charles M., Just J., Huneau C., Magdelenat G., Couloux A., Samain S., Gill B.S., Rasmussen J.B., Barbe V., Faris J.D., Chalhoub B. Duplication and partitioning in evolution and function of homoeologous $Q$ loci governing domestication characters in polyploid wheat. Proc. Natl. Acad. Sci. 2011;108:18737-18742. DOI 10.1073/pnas.1110552108. 